\title{
Children's Understanding of the Rainbow: A Trajectory of Conceptual Development across Middle Childhood
}

\author{
Michael Hast ${ }^{1 *}$ \\ ${ }^{1}$ Institute of Education, St Mary's University Twickenham, UK \\ Received 20 February $2020 \cdot$ Accepted 27 April 2020
}

\begin{abstract}
Background: Surprisingly little is known from a research perspective about the conceptual development of children's understanding of rainbows and rainbow formation. Yet research has shown that teachers tend to overestimate the proportion of students' correct answers in this domain. The present cross-sectional study aims to rectify this shortcoming.

Material and Methods: Primary school children aged 5, 8 and 11 years responded to various questions around rainbows and rainbow formation. The youngest children were also asked to draw pictures. Answers and drawings were evaluated in terms of scientific accuracy.

Results: The outcomes demonstrate age-related increase in reference to scientific explanations of rainbows and their formation. While younger children's understanding was largely inaccurate or limited, the oldest children were more able to demonstrate more sophisticated forms of understanding.

Conclusions: This clarification of the actual levels of conceptual understanding may serve useful when conceptualising pedagogy, lesson plans, or more general curricula in the early science classroom. Even in non-science domains, such as art or storytelling, recognising the differentiation between fact and myth in relation to rainbows could be of value.
\end{abstract}

Keywords: primary science education, conceptual development, cross-sectional research, rainbows

\section{INTRODUCTION}

Conceptual change continues to be a hot topic in the domain of science education. A simple Google Scholar search for "conceptual change" and "science education", for instance, comes up with close to 15,000 search results, and that is when narrowing the search down to only include items from the last five years. As a result, it remains an issue to examine. The particular sub-domains around weather and climate, which have received increased attention over recent years, have also been explored in some detail (see Henriques, 2002, for an overview of relevant studies). Moreover, weather and climate topics play a significant role in classroom-based teaching, finding explicit mention in England's national curriculum for primary education (Department for Education, 2013). However, surprisingly few developmental studies have addressed the specific concept of rainbows and rainbow formation.
While England's national curriculum for science - or indeed for any other subject at this level - does not set out any specific requirements to teach about rainbows or rainbow formation, its non-statutory guidance notes suggest that when teaching about light teachers could also consider 'looking [at] a range of phenomena including rainbows' (Department for Education, 2013, p. 33). A key challenge for instructors, especially in the earlier stages of classroom-based teaching, is that children bring a wide range of ideas about everyday world phenomena with them (Allen, 2014; Hast, 2014; Hast \& Howe, 2012); ideas that are frequently highly resistant to change through instruction (Duit, Treagust, $\&$ Widodo, 2013). Teachers are generally not ignorant of this issue (Gomez-Zwiep, 2008; Hast, 2017). However, in the particular context of rainbows and rainbow formation, while little is known from a research perspective, there is evidence to demonstrate that many primary school teachers in fact tend to overestimate their 


\section{Contribution to the literature}

- This small-scale study demonstrates an evaluation of English primary school children's understanding of rainbows and rainbow formation; an area receiving little coverage to date.

- The findings highlight a wide range of low-level conceptions held at the beginning of primary school, which may stand in contrast to teacher expectations of such understanding.

- Understanding children's scientific and pseudoscientific explanations in this domain has implications for pedagogical practice in primary science, including other concepts where rainbows can be used as illustrations, and even in non-science domains, such as art and storytelling.

students' level of understanding (Malleus, Kikas, \& Kruus, 2016). It is clear, then, that gaining a more complete developmental picture of children's understanding of the rainbow may have important implications for pedagogy in early science education.

So how does children's conceptual understanding of rainbows and rainbow formation vary with age? Only little research has to date aimed to assess this issue ${ }^{1}$. Kikas' (2010) evaluation of 8- to 11-year-olds showed a high level of understanding about when rainbows can be seen and how they are formed in general, but children demonstrated greater difficulty in trying to explain the details of this formation, with no age variations. Other studies confirm such understanding and lack of variation across ages 8 to 13 (Malleus et al., 2016.; Wilhelm \& Henninger, 2012). However, this stands in some contrast with other research showing comparatively high folk rather than scientific beliefs underpinning rainbows and rainbow formation in older children (Okere, Keraro, \& Anditi, 2013), although this insight is based on only a single survey item. Siry and Kremer's (2011) study provides insight into ideas presented by 5- and 6-year-olds, suggesting a wide array of conceptions usually limited to simplistic explanations. Yet because the study's main focus was not the level of conceptual understanding in this age group, it is difficult to gauge what a more systematic evaluation of the concepts might have uncovered.

The above review of the limited existing research in the field evidently suggests mixed results as to what a developmental trajectory in this domain might look like. As a result, the present research aimed to investigate children's conceptual knowledge of rainbows and rainbow formation across the primary school age range. Gaining more detailed insight into the development of such understanding should allow for more careful consideration of how it might reflect particular needs for instruction. Specifically, the research tapped into three different age groups to gauge understanding at beginning, middle and end of the primary school stage to unravel the potential variety of explanations and beliefs, as well as how these might potentially align with instructional recommendations set out by non-statutory guidance and subsequent higher-level scientific concepts.

\section{METHOD}

\section{Participants}

A total of 36 children (22 girls; 14 boys) took part in the study. There were 12 children from Reception $(M=5$ years 5 months), 11 children from Year $3(M=8$ years 7 months) and 13 children from Year $6(M=11$ years 4 months). The children were recruited from a primary school in the Greater London area. To protect the identities of individual children but still be able to report individual data contributions they were each given an alias.

\section{Procedure}

The children took part in small discussion groups where they discussed various questions around rainbows and rainbow formation. Groups ranged in size from three to five children and each only included children from one age group. While four to five seems to be an advocated group size when working with children of these ages (cf. Gibson, 2012) and this was mostly followed, practicalities occasionally resulted in only three children in a group. Discussion groups were carried out in a quiet but openly accessible room in the children's schools and lasted for 20 to 30 minutes. In addition, the 5-year-olds were also asked to draw pictures that included rainbows. Descriptive drawings were included because they may at times provide further insight into children's understanding of scientific phenomena that they are less likely to be able to express at a verbal level (Edens \& Potter, 2003; also see Hast, in press).

\section{Data Analysis}

The focus group conversations and drawings were evaluated around the degree of scientific accuracy of the

1 Two further studies emerged in the literature search process but could not be included in this evaluation. In the first study (Kallery \& Psillos, 2001) one survey question covered rainbows but no specific results about this item are provided. In the second study (Taiwo, Ray, Motswiri, \& Masene, 1999) there was general recognition that scientific explanations about the water cycle increased with age but again, while there were two multiple choice survey items about rainbows, there are no specific results. 
Table 1. Description of and data examples for each level of conceptual understanding

\begin{tabular}{ll}
\hline Level & Description \\
\hline 0 & No or incorrect understanding expressed.
\end{tabular}

1 Some consideration of main scientific factors (e.g. sun and rain are involved) but with no further explanation. Rejection of incorrect ideas.

2a Elaboration on main factors at Level 1, including reference to key scientific concepts, although not always explained correctly.

$2 b \quad$ Accurate scientific expression of main ideas identified at Level 2a.

children's explanations, such as the order of colours, as well as according to any non-scientific conceptions, such as solidity, or mythical representations. Each data contribution was coded according to a pre-defined level of understanding. Children either displayed no or incorrect knowledge (Level 0), limited scientifically acceptable knowledge (Level 1), or accurate scientific understanding (Level 2). Level 2 was further subdivided according to whether key concepts were only expressed (Level 2a), or also explained in some detail (Level 2b). Data examples for each level of conceptual understanding are shown in Table 1.

\section{RESULTS}

Figure 1 summarises the proportion of responses per conceptual level by age group. While only 8 per cent of the 5-year-olds' explanations were considered as Level 2 answers - and all of them $2 \mathrm{a}$ - a little over half of the 8year-olds' and almost all of the 11-year-olds' explanations reached that level. It is worth noting, though, that even amongst the oldest children only 13 per cent of explanations could be classed as having reached Level $2 \mathrm{~b}$. Conversely, across the same age range Level 0 explanations declined from a substantial 41 per cent to a negligible 4 per cent. This developmental
Data example

"There's a planet that has rainbow colours on it and it has a little hole inside, the colours come through that ... so then they drop out."

"They come out when there's rain and sun."

"So when the sun and water reflects them, and when they're together it makes a big bright colour."

"Rainbows are an illusion, they're not really there. It's refraction ... when the sun shines through the raindrops." change stands in some contrast to other cross-sectional studies that seem to indicate no changes with age (Kikas, 2010; Malleus et al., 2016).

Examples of the additional drawings from the 5-yearolds are shown in Figure 2. They represent varying levels of understanding around shape, colour, other factors that need to be present such as sun and rain, and additional misconceptions such as a pot of gold at the end of a rainbow.

\section{Shape}

When asked what shape a rainbow is, all of the children considered the correct visible shape. Most of them referred to an arc, arch or semi-circle. Some of the younger children were not necessarily able to use an appropriate word but then drew the shape with their finger to demonstrate the shape. Their drawings, too, demonstrated an appropriate understanding of shape (see Figure 2). In some instances, older children more correctly referred to the rainbow's shape as actually being a full circle, but that only the top half of that circle, above the ground, is visible. Among the younger children, on the other hand, there was a rather distinct consideration of the rainbow as a semi-circle since "it

\section{$\square$ Level $0 \square$ Level $1 \square$ Level 2a $\square$ Level 2b}

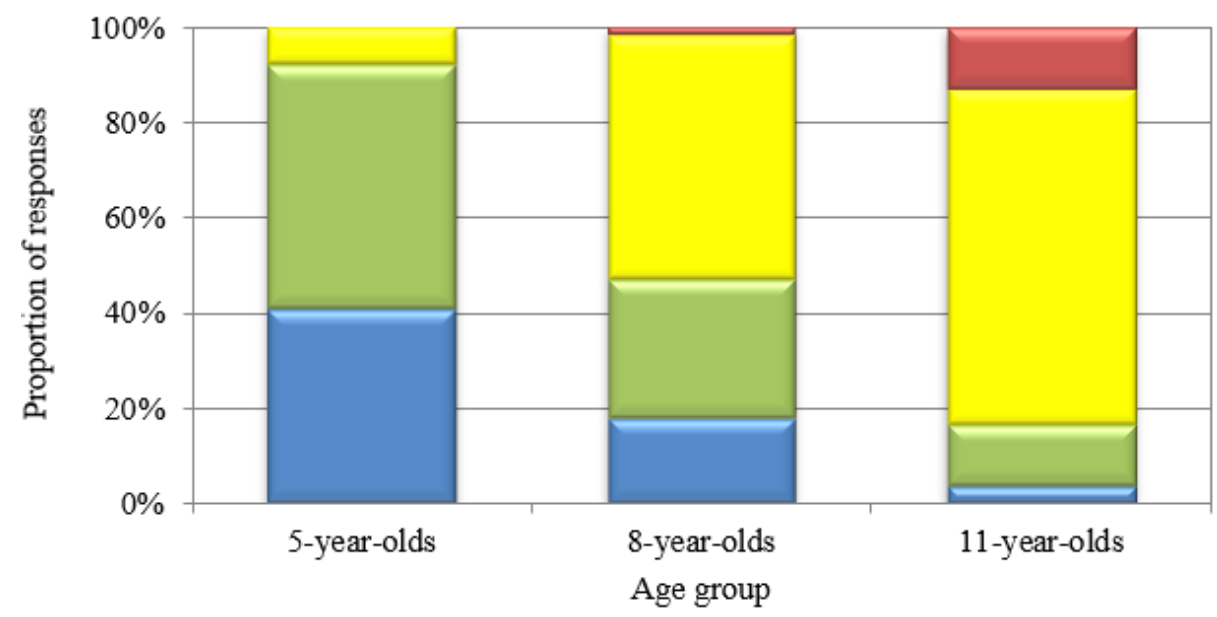

Figure 1. Proportion of responses per conceptual level by age group 


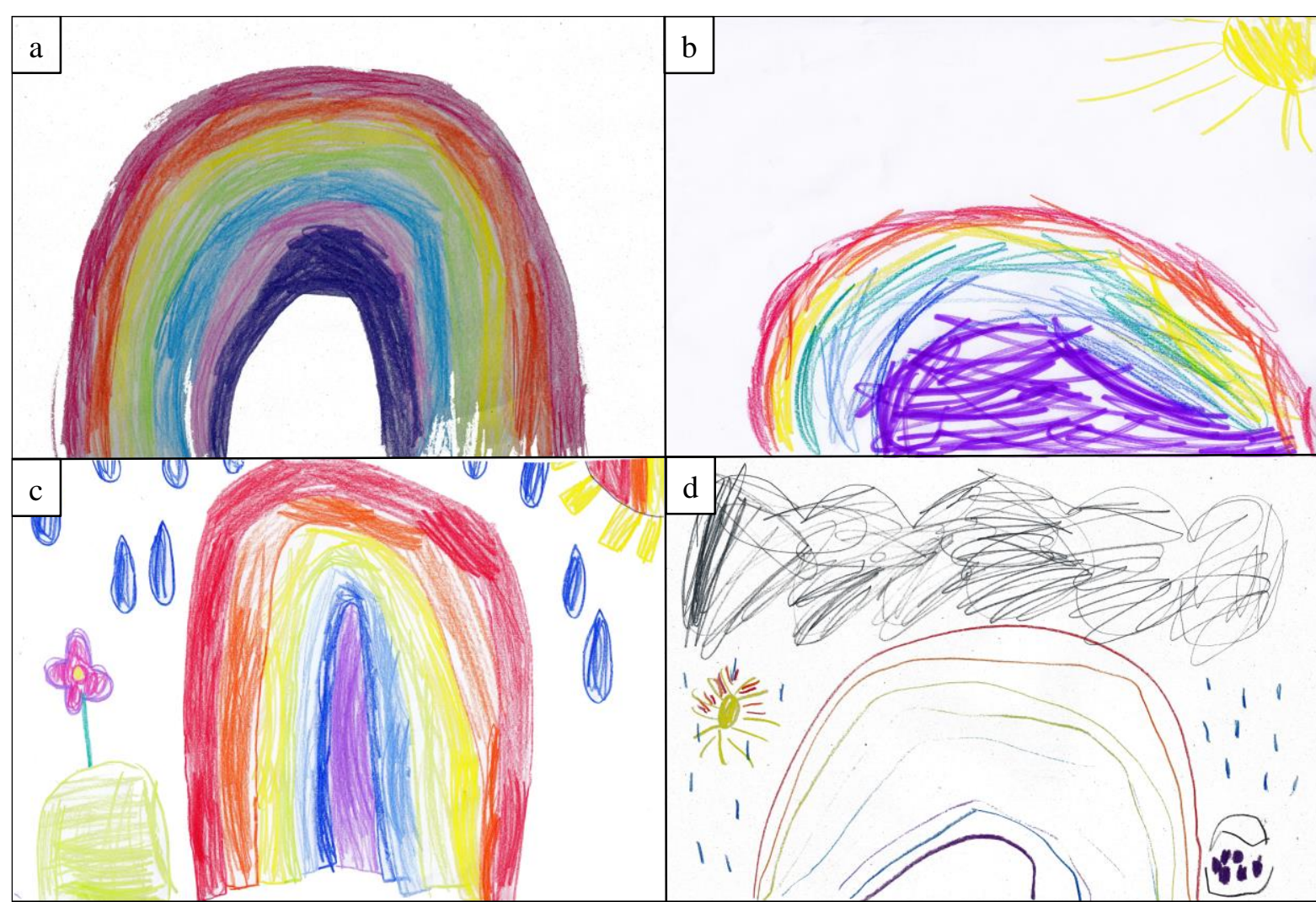

Figure 2. Children's drawings showing various degrees of understanding of rainbows and rainbow formation

never touches the floor ... the ends are on the clouds" (Anya, 5 years).

\section{Colour}

All of the 5-year-olds' drawings had colours in the correct order, even if occasionally colours were missed out or added (see Figure 2). This stands in stark contrast with Wilhelm and Henninger's (2012) evaluation where none of the pupils - who were considerably older coloured the correct order of colours, and only a small proportion was able to select the order when given a choice. The conversations in the present study did not require a listing of colours in order, but frequently children would correctly identify that the red portion of a rainbow was on top. The addition or omission of colours also emerged in some of the verbal accounts. Brian (11 years), for instance, stated that "you don't always see all colours". This is indeed physically possible; rainbows can occur monochromatically in certain conditions, though it is not clear whether this is what Brian was specifically referring to here. On the other hand, other children across the age groups thought they could sometimes see non-conventional colours, such as Katie (8 years) who explained that "sometimes I think I can see pink". This is not physically possible since red and blue, both required to make pink, are at opposite ends of the rainbow colour spectrum.

\section{What Rainbows are Made of}

When asked to explain what rainbows are made of, explanations ranged widely. Amongst the younger children, conceptions that reflected a belief of solidity were common. For instance, Rosie (5 years), whilst pointing to pieces of clear plastic, claimed that rainbows were made from "see-through coloured stuff". Others expressed the belief that rainbows could be touched, even stating having eaten them before - "it tasted like candy floss" (Diamond, 5 years). On the other hand, there were also children in this age group who demonstrated the beginnings of a more appropriate scientific understanding. Anya (5 years), who was in the same discussion group as Diamond, rejected such notions of solidity since "no one has ever been able to touch a rainbow". Elaina's ( 5 years) explanation was, in relative terms, the most accurate amongst the younger children, claiming that "it's in the sky so it's made of clouds". Generally, this line of thought was maintained amongst the older children, though adding reference to more scientific concepts including that rainbows are made of light, gas, or liquid. Ultimately, Jonas' (11 years) outline that "rainbows are an illusion, they're not really there" was perhaps the most ingenious of conceptions.

\section{How Rainbows are Formed}

In trying to explain the formation of rainbows, perhaps the clearest progression with age of depth in children's conceptions can be seen. Some of the younger 
children provided somewhat unusual explanations on rainbow formation, claiming for instance that "there's a planet that has rainbow colours on it and it has a little hole inside, the colours come through that ... so then they drop out" (Aurora, 5 years). However, similar to when asked what rainbows are made of, other children of the same age group showed a more appropriate level of understanding. Patrick (5 years), from the same discussion group as Aurora, followed her notion by explaining that rainbows "come out when there's rain and sun" - though he was unable to go beyond this. Melissa's (8 years) account that "when the sun and water reflects them, and together it makes a big bright colour" expands on this, trying to bring in scientific language as well, though drawing on the incorrect concept of reflection here. Instead, it was once again Jonas (11 years) who demonstrated the most sophisticated conceptual understanding when explaining that "it's refraction ... when the sun shines through the raindrops".

\section{DISCUSSION}

The present small-scale study's aim was to investigate children's conceptual knowledge of rainbows and rainbow formation across the primary school age range. The overall findings suggest that conceptual understanding of rainbows and rainbow formation appears to become more scientifically accurate with increasing age. Unlike previous studies findings (e.g. Kikas, 2010), there were significant changes across all three age groups in terms of demonstrated level of understanding. Notably, even the 5-year-olds' pictures already demonstrate some sophistication in understanding even when they may not yet be able to express ideas at a discursive level (cf. Siry \& Kremer, 2011).

While there was understanding that both sun and rain are needed in order for rainbows to appear, none of the children expressed any awareness where the viewer would need to be in relation to rain - in front of the viewer - and sun - behind the viewer (cf. Wilhelm \& Henninger, 2012). What this demonstrates is that even young children may be fairly competent at explaining rainbows and rainbow formation in general, but they seem to do so from an external position. This may have implications for pedagogy since teaching is often in a manner that places the learner in an external position, such as by looking at photographs that have rain and sun in them at the same time, or at models.

As a whole, the study adds to the as of yet small pool of literature on the understanding of rainbows and rainbow formation in childhood. In particular, it highlights the wide range of low-level conceptions held at the beginning of primary school. In light of Malleus et al.'s (2016) observation that teachers often overestimate children's understanding, this is a crucial finding to make note of. A more detailed analysis will need to evaluate the nature of the breadth of conceptual knowledge. Understanding children's scientific and pseudoscientific explanations may also have implications for other concepts in science where rainbows can be used as illustrations, such as understanding light and colour, or the use of prisms (cf. Department for Education, 2013). Even in non-science domains, such as art and storytelling, recognising the differentiation between fact and myth in relation to rainbows could be of value.

Importantly, this study only offers an initial exploration into the matter at stake. Although this insight is useful to an extent, it is constrained by the geography in which the data were gathered as well as by the sample size. This provides some limit to the generalisability of the outcomes since they cannot be readily applied to other cultural settings - which may, in fact, to some extent help understand the differences observed between the present findings and those from past studies in other cultural contexts. In addition, the study was conducted in an educational context where rainbows only find limited mention in any parts of the national curriculum, and not beyond non-statutory guidance notes. This gives rise to the suggestion that systematic evaluations of pedagogical implementations of this topic could be conducted to examine different approaches to support children's development of conceptual knowledge in this domain.

\section{CONCLUSION}

In sum, this small-scale study suggests there may already be appropriate understanding at various age levels that teachers can draw on in their pedagogy but that they should not overestimate the sophistication of such conceptualisations. Gauging a more coherent picture of this understanding may lead to pedagogical rethinking in the context of formal science teaching towards more successful conceptual change programmes. The present study provides a starting point for instructors to reconsider what is taught when and in what manner - which in turn may have implications for their own confidence in teaching (cf. Hast, 2017).

\section{REFERENCES}

Allen, M. (2014). Misconceptions in primary science. Maidenhead: Open University Press.

Department for Education (2013). Science programmes of study: Key stages 1 and 2. London: HMSO.

Duit, R., Treagust, D. F., \& Widodo, A. (2013). Teaching science for conceptual change: Theory and practice. In S. Vosniadou (Ed.), International handbook of research on conceptual change (pp. 487-503). London: Routledge. 
Edens, K. M., \& Potter, E. (2003). Using descriptive drawings as a conceptual change strategy in elementary science. School Science and Mathematics, 103(3), 135-144. https://doi.org/10.1111/j.19498594.2003.tb18230.x

Gibson, J. E. (2012). Interviews and focus groups with children: Methods that match children's developing competencies. Journal of Family Theory and Review, 4(2), 148-159. https:/ / doi.org/10.1111/ j.1756-2589.2012.00119.x

Gomez-Zwiep, S. (2008). Elementary teachers' understanding of students' science misconceptions: Implications for practice and teacher education. Journal of Science Teacher Education, 19(5), 437-454. https: / / doi.org/10.1007/s10972-008-9102-y

Hast, M. (2014). Collaborating with the 'more capable' self: Achieving conceptual change in early science education through underlying knowledge structures. ReflectED, St Mary's Journal of Education, 3, 18-25.

Hast, M. (2017). Technology and early science education: Examining generalist primary school teachers' views on tacit knowledge assessment tools. International Education Studies, 10(11), 135-147. https://doi.org/10.5539/ies.v10n11p135

Hast, M. (in press). "It is there but you need to dig a little deeper for it to become evident to them": Tacit knowledge assessment in the primary science classroom. Chapter to appear in C. Koh (Ed.), Diversifying learner experiences: A kaleidoscope of instructional approaches and strategies. Singapore: Springer.

Hast, M., \& Howe, C. (2012). Understanding the beliefs informing children's commonsense theories of motion: The role of everyday object variables in dynamic event predictions. Research in Science $\mathcal{E}$ Technological Education, 30(1), 3-15. https:/ / doi.org /10.1080/02635143.2011.653876
Henriques, L. (2002). Children's misconceptions about weather: A review of the literature. School Science and Mathematics, 102(5), 202-215. https://doi.org/ 10.1111/j.1949-8594.2002.tb18143.x

Kallery, M., \& Psillos, D. (2001) Pre-school teachers' content knowledge in science: Their understanding of elementary science concepts and of issues raised by children's questions. International Journal of Early Years Education, 9(3), 165-179. https://doi.org/ 10.1080/09669760120086929

Kikas, E. (2010). Children's thinking: Clouds, rain, and rainbow in children's explanations. Folklore, 44, 113130. https:/ / doi.org/10.7592/FEJF2010.44.kikas

Malleus, E., Kikas, E., \& Kruus, S. (2016). Students' understanding of cloud and rainbow formation and teachers' awareness of students' performance. International Journal of Science Education, 38(6), $993-$ 1011. https:/ / doi.org/10.1080/09500693.2016.1175 683

Okere, M. I. O., Keraro, F. N., \& Anditi, Z. O. (2013). Pupils' cultural interpretations of causes of rainbow in Kenya. Journal of Educational and Social Research, 3(1), 169-177.

Siry, C., \& Kremer, I. (2011). Children explain the rainbow: Using young children's ideas to guide science curricula. Journal of Science Education and Technology, 20(5), 643-655. https://doi.org/10.1007 / s10956-011-9320-5

Taiwo, A. A., Ray, H., Motswiri, M. J., \& Masene, R. (1999). Perceptions of the water cycle among primary school children in Botswana. International Journal of Science Education, 21(4), 413-429. https:/ / doi.org/10.1080/095006999290633

Wilhelm, T., \& Henninger, P. (2012). Schülervorstellungen zum Regenbogen [Pupil's conceptions of the rainbow]. Didaktik der Physik Frühjahrstagung - Mainz 2012. Retrieved on June 14, 2019, from http://www.phydid.de/index.php/ phydid-b/article/view/334/457

\section{http://www.ejmste.com}

